\title{
Recovery from Idiopathic Facial Paralysis (Bell's Palsy) Using Photobiomodulation in Patients Non-Responsive to Standard Treatment: A Case Series Study
}

\author{
Claudio Pasquale ${ }^{1, *} \mathbb{\infty}$, Anatoliy Utyuzh ${ }^{2}$, Maria Vladimirovna Mikhailova ${ }^{2}$, Esteban Colombo ${ }^{1} \mathbb{D}$ and \\ Andrea Amaroli 1,2 (D) \\ 1 Department of Surgical and Diagnostic Sciences, University of Genoa, 16132 Genoa, Italy; \\ esteban.colombo92@gmail.com (E.C.); andrea.amaroli.71@gmail.com (A.A.) \\ 2 Department of Orthopedic Dentistry, Faculty of Dentistry, First Moscow State Medical \\ University (Sechenov University), 119991 Moscow, Russia; anatoliy.utyuzh@gmail.com (A.U.); \\ stom-maria@mail.ru (M.V.M.) \\ * Correspondence: clodent@gmail.com; Tel.: +39-010-353-7309
}

check for updates

Citation: Pasquale, C.; Utyuzh, A.; Mikhailova, M.V.; Colombo, E.; Amaroli, A. Recovery from Idiopathic Facial Paralysis (Bell's Palsy) Using Photobiomodulation in Patients Non-Responsive to Standard Treatment: A Case Series Study. Photonics 2021, 8, 341. https:// doi.org/10.3390/photonics 8080341

Received: 28 July 2021

Accepted: 18 August 2021

Published: 20 August 2021

Publisher's Note: MDPI stays neutral with regard to jurisdictional claims in published maps and institutional affiliations.

Copyright: (c) 2021 by the authors. Licensee MDPI, Basel, Switzerland. This article is an open access article distributed under the terms and conditions of the Creative Commons Attribution (CC BY) license (https:// creativecommons.org/licenses/by/ $4.0 /)$.

\begin{abstract}
Diminished facial movement and marked facial asymmetry can lead to a consistent psychological burden. Bell's palsy (BP) is one of the most common causes of facial nerve illness, which comes with unilateral acute facial paresis. Nowadays, no clear guidelines for treating BP are available. We carried out a case series study to test the efficacy of photobiomodulation (PBM) therapy in patients with BP non-responsive to standard treatment. The study was experimentally performed at the Department of Surgical and Diagnostic Sciences, University of Genoa (Genoa, Italy), in accordance with case report guidelines. Patients were referred to our department by colleagues for evaluation to be included in the case series because no consistent improvement was observed at least 3 months from the diagnosis of BP. All the patients interrupted their pharmacological therapy before the initiation of PBM therapy. PBM therapy $(808 \mathrm{~nm}, 1 \mathrm{~W}$ irradiated in continuous-wave for $60 \mathrm{~s}$ on spot-size $1 \mathrm{~cm}^{2} ; 1 \mathrm{~W} / \mathrm{cm}^{2} ; 60 \mathrm{~J} / \mathrm{cm}^{2}$; and $60 \mathrm{~J}$ ) was administered every 2 days until complete resolution. Evaluation of the House-Brackmann scale was performed before and after treatments. Fourteen patients were screened as eligible for the study. Patients were Caucasians (36\% females and $64 \%$ males) with a mean age \pm standard deviation of $56.07 \pm 15.21$ years. Eleven patients out of 14, who experienced BP a maximum of 6 months, completely recovered through PBM. The three patients that did not show improvement were those who had experienced BP for years. PBM could be a supportive therapy for the management of BP in patients non-responsive to standard treatment. However, randomized controlled trials are necessary to sustain our encouraging results, exclude bias, and better explain the boundary between the time from diagnosis and the recovery of BP through PBM therapy.
\end{abstract}

Keywords: facial nerve; facial paralysis; idiopathic facial palsy; chronic pain; low-level laser therapy; light therapy; alternative cure; inflammation; tissue regeneration

\section{Introduction}

Facial expression plays a pivotal role in social relationships and self-esteem [1]. Persistence of diminished facial movement and marked facial asymmetry can lead to a consistent psychological burden, social alienation, and depression for patients, which may result in decreased productivity and higher health care expenses [2,3].

Bell's palsy (BP) is one of the most common causes of facial nerve illness. Its incidence is around 11-40 out of 100,000 individuals according to the literature [4-6]. Nowadays, the diagnosis is mainly based on exclusion criterion and functional assessments through scales of severity, while the instrumental investigation is considered only because of possible iatrogenic, tumoral, or traumatic origin [7]. Indeed, many conditions, such as GuillainBarré syndrome, Ramsay Hunt syndrome, reactions to intranasal influenza vaccines, Lyme 
disease, sarcoidosis, cholesteatoma, tumors, and general structural lesions in the parotid gland and ear can mimic the symptoms of BP $[4,5,8]$. However, although these disorders can represent isolated facial nerve palsies, they usually cause additional problems that distinguish them from it $[4,5,8]$. Usually, $\mathrm{BP}$ is accompanied by unilateral acute facial paresis that evolves in 24-48 $\mathrm{h}$ [4] and reaches maximum facial weakness in 3-7 days [4,5,8].

The aetiology and pathophysiology of BP have long been debated. An increasing number of authors no longer speak of idiopathic facial paralysis in the current state of knowledge, but rather of herpetic facial paralysis [9]. In fact, clinical observations and experimental data seem to describe $\mathrm{BP}$ as a result of the reactivation of the Herpes simplex virus isoform 1 (HSV-1) and/or Herpes zoster virus (HZV) [8,10]. Corticosteroid therapy is universally recognized for improving the prognosis of BP [11,12]; its effectiveness is linked to anti-oedema activity and to the reduction of inflammation underlying the autoimmune phenomena affecting the myelin sheath. Many authors consider combining them with antiviral agents as valid [12], and the addition of antibiotic therapy may be of benefit [4]. However, a careful systematic review of the literature by Tiemstra and collaborators [4] showed the reliability of antivirals was not superior to placebo, and treatment with corticosteroids seemed to have, in many cases, small or insignificant statistical reduction of symptoms after 6 months of treatment. Referring to the surgical approach, it consists of a decompression procedure and should be reserved for cases with facial nerve degeneration greater than $90 \%$ by electroneurography/electromyography analysis $[4,13,14]$.

Additionally, published studies have suggested the benefit of acupuncture [15], but systematic reviews $[2,4,5,8]$ have pointed out flaws in some study designs. Therefore, there is no consensus on this alternative therapy. However, recently, Xu et al. [16] showed the utilization of glucocorticoid treatment along with acupuncture to be promising. Basically, the non-univocal results generated confusion, resulting in no clear guidelines for treating BP being available nowadays [8].

Recently, Javaherian et al. [17] reviewed the possible use of photobiomodulation $(\mathrm{PBM})$ in the treatment of BP and concluded a beneficial effect on recovery for patients with subacute BP; adverse effects were not described. Furthermore, in our previous systematic review [18], we showed PBM can affect the mitochondrial activity and the bioenergetics of cells, resulting in an improvement in the recovery from trigeminal diseases.

Indeed, PBM, previously known as low-level laser therapy (LLLT), acts through a transfer of energy from photons, in the visible and near-infrared (NIR) range of wavelengths, to photoacceptors [18-21]. The energy retained in the photoacceptor may then induce a photochemical reaction in the cell that increases the production of ATP, influencing cell metabolism [18,20]. Actually, at $800 \mathrm{~nm}$, the cytochrome c oxidase (complex IV) of the mitochondrial respiratory chain has evidence of absorption of its energy peak, depending on its precise oxidation state $[22,23]$. Complexes I and II are not affected by those wavelengths, while complex III is poorly stimulated [18,23]. However, PBM has limitations in terms of consistency because of both the physical and physiological traits of tissue-light interactions and the features of standard delivery instruments (probes, fiber, or hand-piece (HP)) $[24,25]$. In this respect, a novel HP has been patented and manufactured to improve the standardization of the delivery of PBM therapy [25]. Authors have shown this HP, irradiating with a flat-top (FT) beam profile, is able to generate a homogeneous and constant power on the beam spot-area [23,25], which is not affected by the distance from the target $[24,25]$. In vitro evidence has shown PBM therapy irradiated with the FT-HP is more effective, predictable, and repeatable than with standard probes [24,25]. Through the use of the FT-HP, a therapy, consisting of $808 \mathrm{~nm}$ of wavelength and $1 \mathrm{~W}$ of power irradiated for $60 \mathrm{~s}$ in continuous-wave $(\mathrm{CW})$ on a spot-size area of $1 \mathrm{~cm}^{2}$ to generate a fluence of $60 \mathrm{~J} / \mathrm{cm}^{2}$ and a power density of $1 \mathrm{~W} / \mathrm{cm}^{2}$, was selected and characterized on isolated mitochondrial [19,20,23,25], cellular [26,27], and animal models [28,29], as well as on humans [30,31].

Therefore, according to our previous works $[25,30]$, we hypothesize that $808 \mathrm{~nm} 1 \mathrm{~W}$, $1 \mathrm{~W} / \mathrm{cm}^{2}$, and $60 \mathrm{~J} / \mathrm{cm}^{2}$ laser therapy, irradiated through the FT-HP, could support the 
recovery of patients affected by BP. Therefore, the predictor variable of our research was our PBM therapy through higher power and fluence, irradiated through the FT-HP [25]. The primary endpoint was the improvement in the symptoms of BP, defined by the HouseBrackmann scale, in patients with no response to standard treatment. The secondary endpoint was the detection of any adverse effects up to 12 months follow-up.

\section{Materials and Methods}

\subsection{Patients' Information and Eligibility}

Our case series study was experimentally performed at the Department of Surgical and Diagnostic Sciences (DISC), University of Genoa (Genoa, Italy), in accordance with case report guidelines.

Before arriving at the DISC, all patients were diagnosed with BP within 3 days of the onset of symptomatology [2] by specialized physicians that followed the Guideline Development Group [32]. Figure 1 shows a drawing of a typical patient affected by BP. In accordance with the medical record, information on patients was available to our team. Basically, the severity of the illness was evaluated and quantified through the HouseBrackmann scale [33], an accredited clinical tool employed to document the degree of facial paralysis and to predict the probability of recovery. Electromyography $[4,13,14]$ excluded management by surgery; therefore, patients were immediately treated with corticosteroids and acyclovir $[4,8,33,34]$. Additionally, the use of eye lubricant was suggested. After 2 weeks on medication, the patients who did not show improvement were reviewed by specialized physicians to carefully exclude other conditions that mimic BP, such as Guillain-Barré syndrome, Ramsay Hunt syndrome, Melkersson-Rosenthal syndrome, Sjogren's syndrome, Lyme disease (not endemic in our country), sarcoidosis, stroke, multiple sclerosis, cholesteatoma, tumors, and general structural lesions in the parotid gland and ear, according to the literature $[4,5,8]$. The use of intranasal influenza vaccines was also excluded.

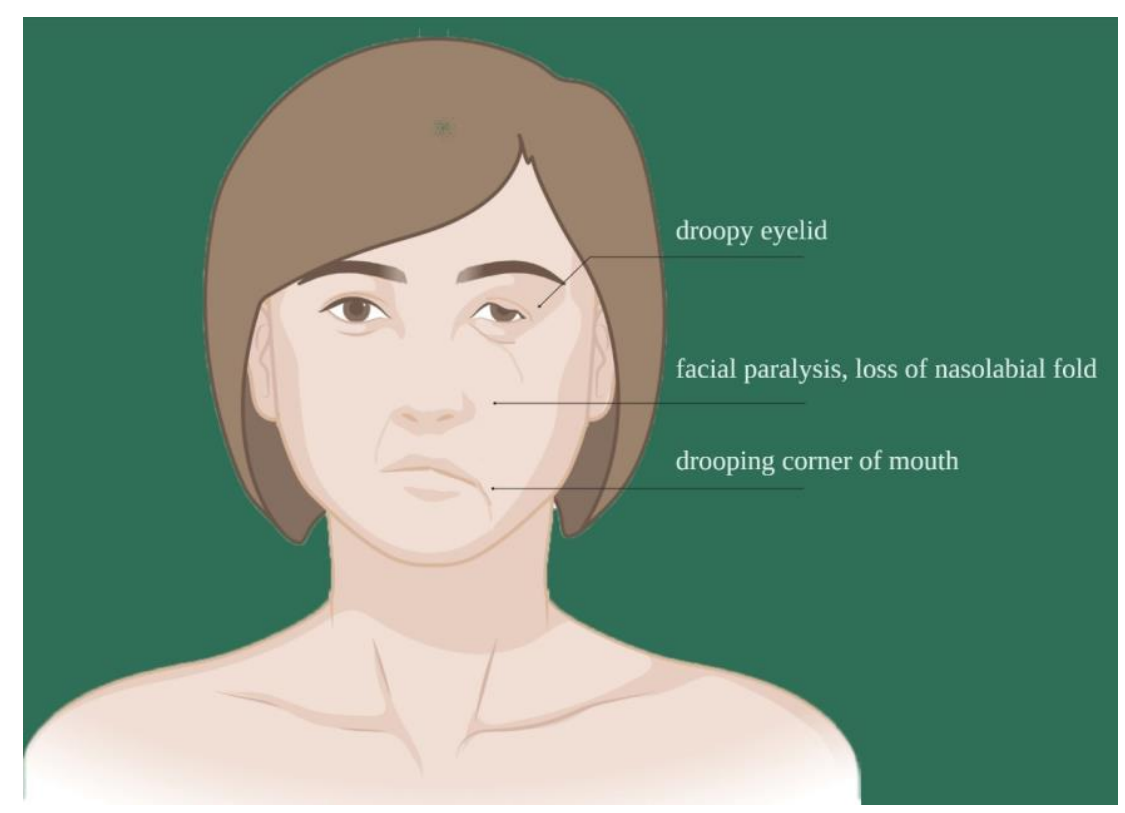

Figure 1. Bell's palsy is a unilateral facial peripheral palsy of the facial nerve that results in muscle weakness on one side of the face affected. The drawing shows the typical aspect and consequences of a patient affected by it. Image created with BioRender.com.

Confirmation of BP was followed by cycles of administration of the previous pharmacological cure. 
Patients were referred to our department by colleagues for evaluation to be included in the case series because no consistent improvement was observed by at least 3 months from the diagnosis of BP.

Before inclusion in the case series study, the patients were re-evaluated and the HouseBrackmann scale was re-assigned.

Patients were considered eligible if BP was confirmed and they were negative for diabetes, human immunodeficiency virus (HIV) and high blood pressure. Pregnant women and patients younger than 18 years were excluded. No discrimination on the grounds of sex was made. Conversely, because of $808 \mathrm{~nm}$ laser light absorption by melanin [35], only Caucasian people were considered suitable for the study. The patients stopped their pharmacological treatment.

\subsection{Procedures}

In accordance with our previous in vitro [23,25-27] preclinical [28,29] and clinical [30] studies, an $808 \mathrm{~nm}$ diode laser device (Doctor Smile, LAMBDA Spa, 36100 Vicenza, Italy) equipped with the AB-2799 HP (Doctor Smile, LAMBDA Spa, 36100 Vicenza, Italy) able to irradiate through an FT beam profile was used.

PBM therapy was administered through the power of $1 \mathrm{~W}$ irradiated in $\mathrm{CW}$ for an exposure time of $60 \mathrm{~s}$ and on a spot-size of $1 \mathrm{~cm}^{2}$, which allowed generating a power density of $1 \mathrm{~W} / \mathrm{cm}^{2}$ and a fluence of $60 \mathrm{~J} / \mathrm{cm}^{2}$ (energy administered $=60 \mathrm{~J}$ ). To complete the therapy session, a total of seven points were irradiated in contact. The laser parameters and treatment are are shown in Figures 2 and 3.

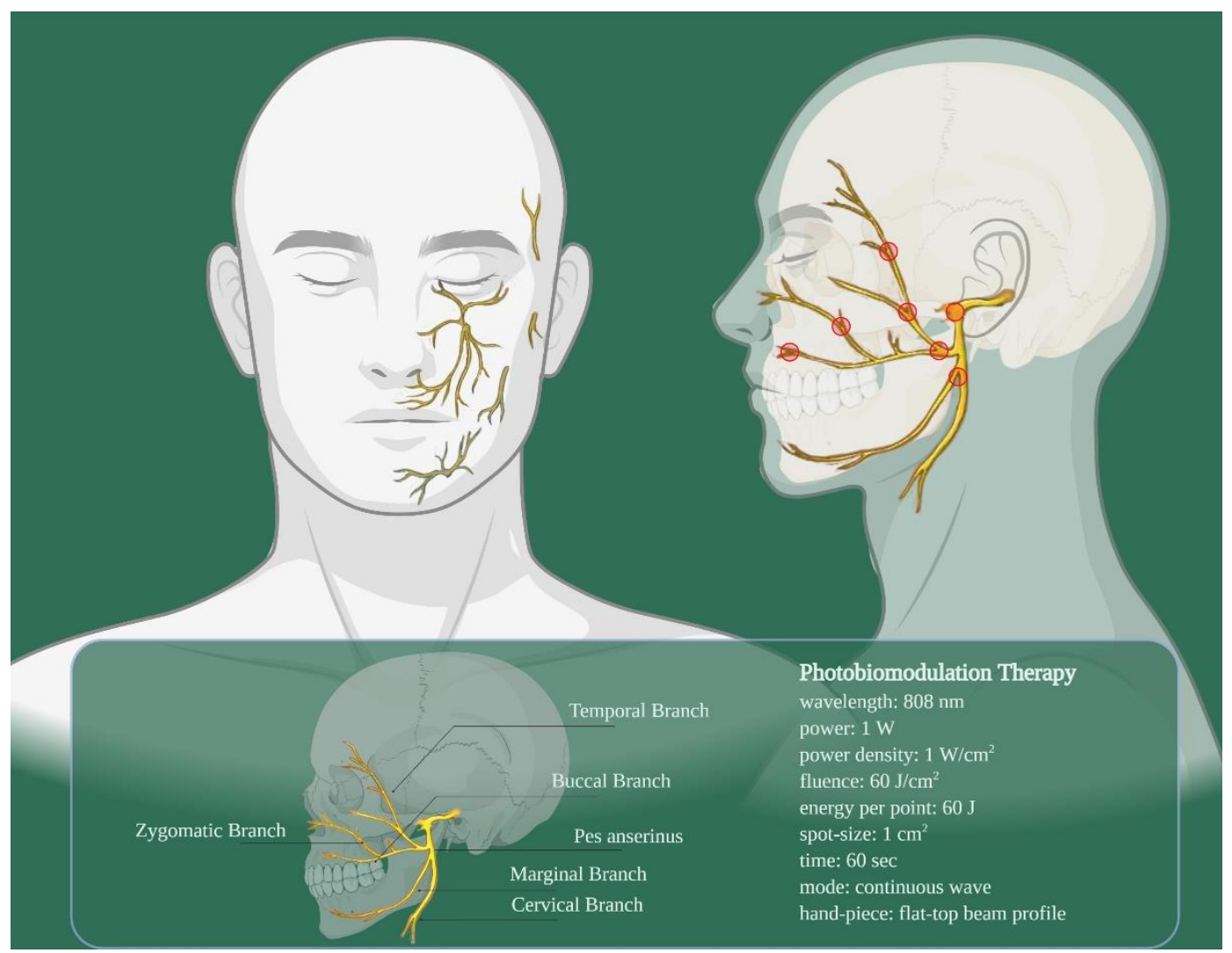

Figure 2. Design of the photobiomodulation therapy irradiation area and parameters. In yellow, the frontal and lateral representations of the facial nerve and its branches. The red circles along the facial nerve branches indicate the points where the therapy was administered in every session. Image created with BioRender.com. 


\begin{tabular}{|c|c|}
\hline \multicolumn{2}{|c|}{ Laser parameters and treatments } \\
\hline manufacturer & Dotor Smile s.p.a. \\
\hline model identifier & Wiser \\
\hline type of emitter & Diode-GaAl-As \\
\hline hand-piece & AB-2799 Flat-Top* \\
\hline year procedure & $2020-2021$ \\
\hline wavelength & $808 \mathrm{~nm}$ \\
\hline pulse mode & continuous-wave \\
\hline power & $1 \mathrm{~W}$ \\
\hline power density & $1 \mathrm{~W} / \mathrm{cm}^{2}$ \\
\hline energy & $60 \mathrm{~J}$ \\
\hline fluence & $60 \mathrm{~J} / \mathrm{cm}^{2}$ \\
\hline exposure duration & $60 \mathrm{~s}$ \\
\hline beam spot size at target & $1 \mathrm{~cm}^{2}$ \\
\hline irradiation mode & contact \\
\hline point irradiated per session & 7 \\
\hline energy irradiated per session & $420 \mathrm{~J} / 7$ points \\
\hline number and frequency of treatment session & every 2 days until complete resolution ${ }^{* *}$ \\
\hline
\end{tabular}

Figure 3. Laser parameters and treatments session design. The laser therapy was irradiated through a flat-top beam profile hand-piece, every 2 days until complete resolution. Previously, we showed [25] the flat-top hand-piece * is able to maintain constant power and beam spot size from contact to many centimeters away allowing for improved clinical consistency during PBM treatments delivery. ${ }^{* *} \mathrm{BP}$ resolution was experienced after different treatment sessions, from 8 up to 18 . Image created with BioRender.com.

The precision of the laser therapy parameter was secured by the Pronto-250 power metre (Gentec Electro-Optics, Inc. G2E Quebec City, QC, Canada).

Adverse events due to possible undesirable thermal effects were avoided by monitoring the irradiation with a thermal camera, FLIR ONE Pro-iOS (FLIR Systems, Inc. designs, 97070 Portland, OR, USA.) (dynamic range: $-20^{\circ} \mathrm{C} /+400{ }^{\circ} \mathrm{C}$; resolution $0.1^{\circ} \mathrm{C}$ ) [25].

PBM therapy was administered every 2 days until complete resolution. Special protective glasses were used to keep patients and operators safe.

The patients were screened before the irradiation of the PBM therapy, and the HouseBrackmann scale was used in the evaluation of every therapy session.

At the end of therapy, patients were re-examined at the following follow-up visits: day 15, 1 month, 3 months, 6 months, and 12 months.

Images were obtained by the Canon EOS 450 camera, with a $100 \mathrm{~mm}$ lens (Canon Italia S.p.A, 20063 Cernusco sul Naviglio, Milan, Italy). The images were acquired in a standard condition of illumination, exposition, distance, and tilt angle.

\subsection{Outcomes}

The predictor variable of our research was the PBM through higher power and fluence irradiated through the FT-HP [25]. The primary endpoint was the improvement in BP, as evaluated by the House-Brackmann scale, in patients with no response to standard treatment. The secondary endpoint was detecting any adverse effects up to the 12-month follow-up visit.

\section{Results}

\subsection{Participants}

Between January 2020 and May 2021, 14 patients were screened as eligible for the study. Patients were Caucasians ( $36 \%$ females and $64 \%$ males) with a mean age \pm standard deviation of $56.07 \pm 15.21$ years. Characteristics of the patients and their recovery after 
treatment with PBM therapy are shown in Figure 4. BP was diagnosed no more than 3 days after the onset of symptomatology by colleagues. Patients were immediately treated with corticosteroids and acyclovir through cycles of therapy from a minimum of 36 days to a maximum of 75 days (Figure 4, drug administration). All the patients interrupted their pharmacological therapy, according to the advice of specialized physicians, because no significant recovery was observed. In all, $68 \%$ of the patients manifested insurgence of side effects because of the prolonged administration of drugs. Patients were then referred to our department. Therefore, when included in the study, the elapsed time from the diagnosis of BP was from a minimum of 3 months to a maximum of 4 years (Figure 4, "time after a diagnosis" column). Consequently, patients had interrupted their pharmacological treatment from a minimum of 15 days up to a maximum of years (Figure 4 , "time after a diagnosis" vs. "drug administration" column). Concerning the 14 enrolled patients, a specialized physician confirmed the diagnosis of BP and the House-Brackmann scale was re-evaluated and confirmed (Figure 4, "House-Brackmann scale before"). No familial predisposition was described by patients.

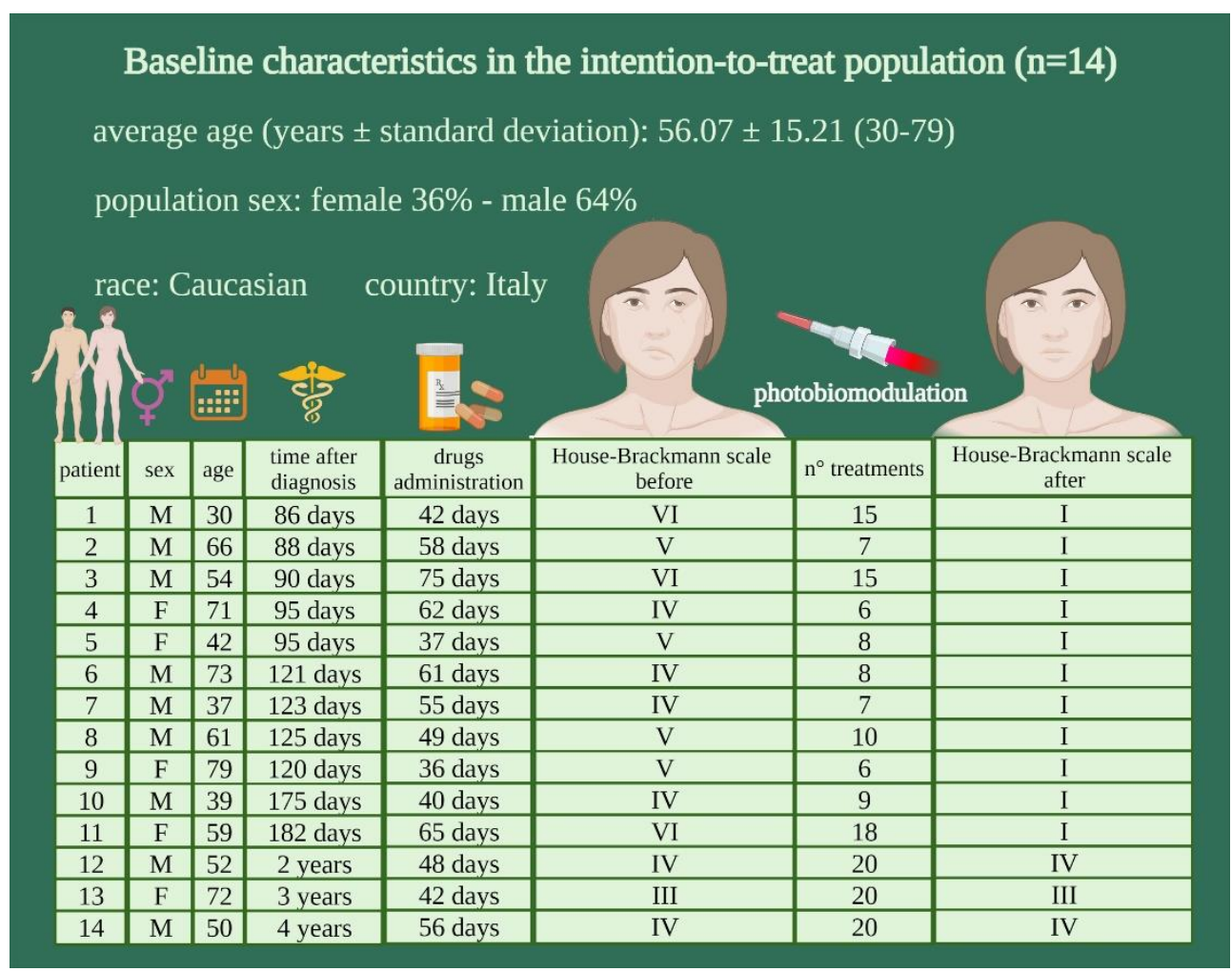

Figure 4. The figure shows the baseline information about the 14 patients enrolled for the case series study. The 14 patients received Bell's palsy diagnosis months before to be included in the study (time after diagnosis). The 14 patients followed the therapy as indicated in the column "drug administration" and interrupted it before the PBM dosing. The House-Brackman score was evaluated before (House-Brackman scale before) and after (House-Brackman scale after) the laser treatment $\left(\mathrm{n}^{\circ}\right.$ treatments).

\subsection{Primary and Secondary Endpoints Evaluation}

Concerning the primary endpoint, 11 out of 14 patients (patients 1-11) completely recovered after treatment with PBM (Figure 4, "House-Brackmann scale after"; Figure 5). The three patients that did not show improvement (patients 12-14) were those who had experienced palsy for years. Variable numbers of treatments (Figure 4, " $\mathrm{n}^{\circ}$ treatment") were necessary to reach complete recovery (House-Brackmann scale I), according to the severity of the disease rather than the time elapsed from the diagnosis. However, after 
a long time, the therapy also appeared ineffective for moderate and moderately severe House-Brackmann scale score III and IV, respectively (patients 12-14).

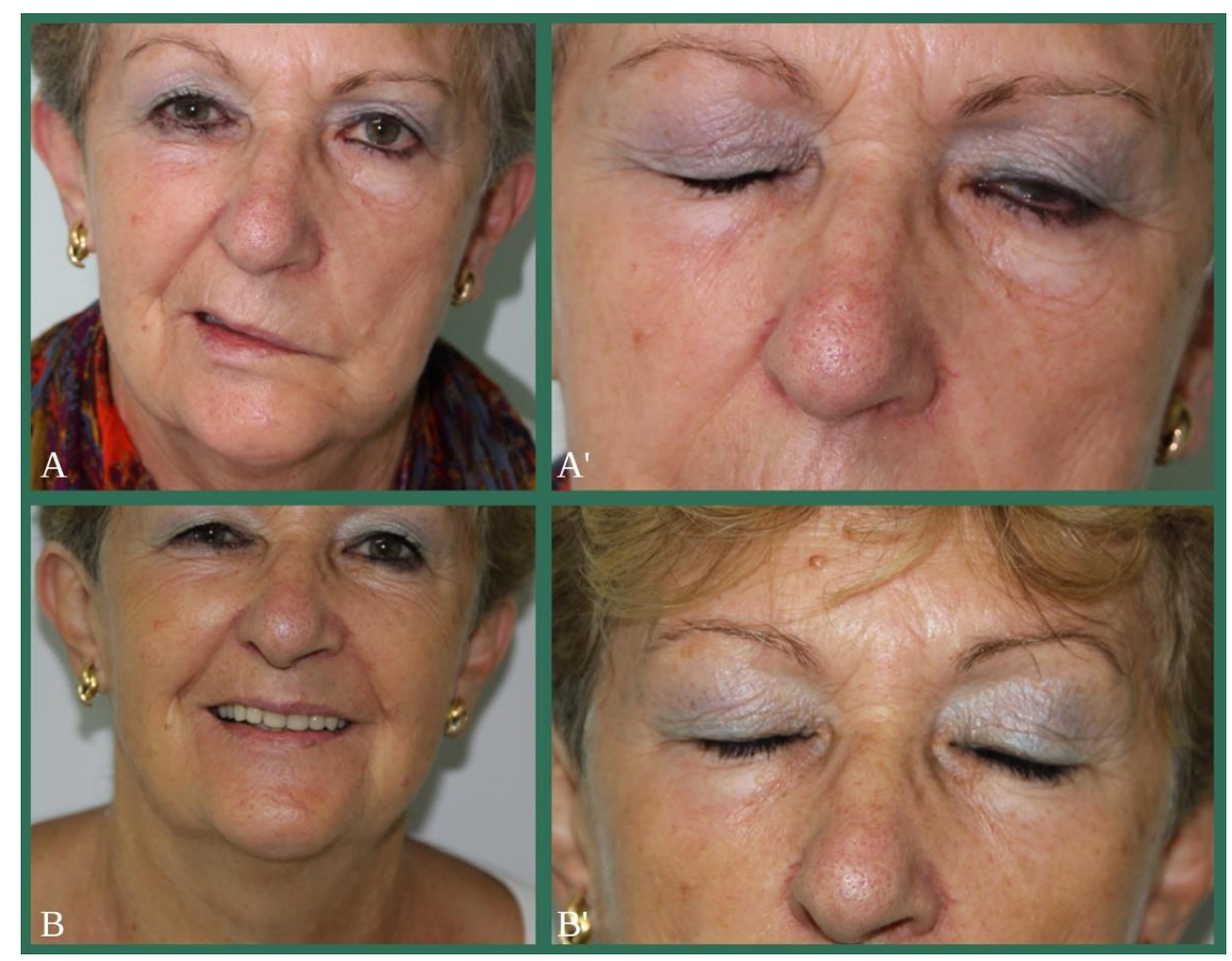

Figure 5. The figure shows the patient $\mathrm{n}^{\circ} 9$ of Figure 4, before $\left(\mathbf{A}, \mathbf{A}^{\prime}\right)$; House-Brackman scale value V) and after 9 treatments of PBM $\left(\mathbf{B}, \mathbf{B}^{\prime}\right)$; House-Brackman scale value I).

In patients 1-11, after three sessions, there was already an evident improvement observed in the closure of the eye and in the partial restoration of the symmetry of the mouth, especially in the expression of the smile. As regards the secondary endpoint, no recrudescence of the disease or adverse effect was evidenced during follow-up. The ineffectiveness of PBM therapy in patients 12-14 was also confirmed during follow-up.

\section{Discussion}

BP usually resolves within weeks or months [2]. However, in approximately $25 \%$ of patients, moderate-to-severe facial damage and discomfort may persist [36]. Precocious pharmacological treatment of BP seems to support recovery from the illness, but systematic reviews $[2,4,5,8]$ show a positive contribution is of modest extent. Meanwhile, a surgical approach appears controversial [2]. Alternative approaches have been proposed [37,38], but in this case, the effective improvement with respect to placebo is still under evaluation [38]. Recently, PBM was proposed as an approach in the treatment of BP [17]. Tanganelli et al. [39], on a single patient, concluded that a single session of PBM therapy was an effective option for those affected by BP. Kumar [40] concluded, in a study on five patients, that class IV level laser therapy can support the medical management of $\mathrm{BP}$, including cases with adverse effects from corticosteroids. However, their recovery was prevalently a partial result [40]. Aghamohamdi et al. [41] showed that the HouseBrackmann grading scale ameliorates to grade I (18 cases), grade II (six cases), and grade IV (six cases) through 12 sessions of PBM on 30 patients with diabetes. Lastly, Ordahan and Karahan [42] observed positive effects of PBM associated with expression exercises on 23 patients treated in the subacute phase of the disease. Likewise, our data confirmed the consideration of PBM as a suitable therapy for BP management. Indeed, our data for the first time pointed out that PBM can support the recovery of patients affected by BP who 
had no response to pharmacological treatment, even when the irradiation began months after the diagnosis.

Essentially, patients with House-Brackmann scale scores from IV-VI, who started PBM therapy at 3, 4, and 6 months after the diagnosis, recovered to a score of I, after 6-18 treatment sessions.

With some limitations due to the experimental setup of a case series, data pointed out that, if the same PBM therapy parameter was irradiated, the number of treatments necessary to reach complete recovery were in accordance with the severity of the disease rather than the time elapsed from the diagnosis, assuming no more than 6 months had passed after the diagnosis of BP.

Literature suggests the Herpes virus can affect neural dysfunction through activation of apoptotic pathways and intra-axonal degradation $[43,44]$. The expressions of p53 proteins, modulators of apoptosis (PUMA), and the selective androgen receptor modulator (SARM) pathway seem to be a consequence, triggering axon degeneration $[43,44]$. Furthermore, the regulation of extracellular signal-regulated kinase (ERK) and aquaporin-1 (AQP1) proteins can modulate morphological changes in Schwann cells, supporting the progression of facial nerve oedema [45]. In this context, authors have shown that PBM can regulate p53 and PUMA in human dermal fibroblasts and human acinar cells [46,47], as well as AQP1, mediating its effects on human erythrocytes [48].

Recent evidence by authors [2,49] converged with the hypothesis that cases of BP unable to be resolved could be correlated with ischaemia and its sequelae, followed by anomalies to the facial nerve sheath that hamper recovery. In this case, PBM could also serve as a promising therapeutic strategy as observed for functional recovery after global cerebral ischaemia [50]. Additionally, our team previously demonstrated the effectiveness of the therapy employed for BP $\left(808 \mathrm{~nm}, 1 \mathrm{~W} ; 60 \mathrm{~J} / \mathrm{cm}^{2}\right)$ in promoting angiogenesis [51]. Additionally, we recently reviewed the consistent support of PBM in endothelial dysfunction [52].

However, in our revision of the literature on trigeminal nerve damage [18], a close connection between mitochondrial bioenergetics and PBM was demonstrated, which should also be kept in mind for BP.

In support of this assumption, Moriyama and collaborators [53] "observed that the gene expression in BP changes with the degree of facial nerve palsy. Especially, muscle, neuron, and energy category genes tended to fluctuate with the degree of facial nerve palsy". Furthermore, Persson et al. [54] suggested that the activity of sodium and calcium channels contributes to axonal degeneration after mitochondrial dysfunction.

Particularly in BP with House-Brackmann score $>$ IV, facial nerve conduction may be largely abolished, leading to very little metabolic energy production with a consistent consequence on nerve and muscle regeneration. This can, in part, explain the total or partial unresponsiveness of our patients to not only the pharmacological cure but also the effectiveness of our PBM therapy [53].

In fact, we previously showed the ability of $808 \mathrm{~nm} 1 \mathrm{~W}, 1 \mathrm{~W} / \mathrm{cm}^{2}$ and $60 \mathrm{~J} / \mathrm{cm}^{2}$ to modulate the calcium homeostasis affecting mitochondria bioenergy production $[26,27]$, through the mitochondrial respiratory chain $[23,25,55,56]$, cell metabolism $[26,50]$, and inflammatory cell pathways [57], to promote cell proliferation [50,55,57], tissue regeneration [28,30,58], and release of neurotransmitters [59]. Lastly, the target of PBM therapy and the alteration of energy category genes in both moderate and severe BP could also explain why our PBM therapy was unsuccessful if performed more than 1 year after the onset of palsy.

Likewise, Moriyama et al. [53] concluded that both facial nerve neurorrhaphy and nerve grafting fail in patients that had experienced BP for 1 year or more.

The main limitation of our study is that, because of the case series design, our data have no control and comparative statistical analysis cannot be performed [60]. Therefore, our work has a risk of bias and is limited in the sample size calculation. 
However, the medical history of our patients may support the assumption that the influence of drugs or natural recovery on the results could probably be excluded.

\section{Conclusions}

In conclusion, PBM through $808 \mathrm{~nm} 1 \mathrm{~W}, 1 \mathrm{~W} / \mathrm{cm}^{2}$ and $60 \mathrm{~J} / \mathrm{cm}^{2}$ laser therapy, irradiated with the FT-HP, complied with both the primary and secondary endpoints. It is noteworthy that the relatively higher energy used in our work was supported by the flat-top hand-piece feature, which, as shown in our previous work [25], has a uniform distribution of the power density compared to Gaussian beam profile of standard both fibers and hand-pieces; thermal increase is limited. Therefore, PBM could be a supportive therapy for the management of BP in patients non-responsive to standard treatment. However, randomized controlled trials are necessary to sustain our encouraging results and exclude bias, as well as better explain the boundary between the time from diagnosis and the recovery of BP through PBM therapy.

Author Contributions: Conceptualization, C.P. and A.A.; methodology, C.P. and A.A.; software, M.V.M. and A.A.; validation, C.P. and A.A.; formal analysis, A.A.; investigation, C.P. and A.U.; resources, C.P.; data curation, A.A. and E.C.; writing—original draft preparation, C.P. and A.A.; writing-review and editing, C.P., A.U., M.V.M., E.C. and A.A.; supervision, A.U. and A.A.; project administration, A.A.; funding acquisition, C.P. and A.A. All authors have read and agreed to the published version of the manuscript.

Funding: This research received no external funding.

Institutional Review Board Statement: This study followed the Declaration of Helsinki with regard to medical protocol and ethics, and the Regional Ethical Review Board of DISC, University of Genoa approved the study (Unige-DISC-protocol number 0015094).

Informed Consent Statement: Informed consent was obtained from all subjects involved in the study.

Data Availability Statement: Data available on request from the authors.

Acknowledgments: We express our deepest appreciation to Alberico Benedicenti, Valentino Valentini and Davina Bartoli for their support in the diagnosis.

Conflicts of Interest: The authors declare no conflict of interest.

\section{References}

1. Pouwels, S.; Beurskens, C.H.; Luijmes, R.E.; Ingels, K.J. Clinical importance of smiling in patients with a peripheral facial palsy. J. Plast. Reconstr. Aesthet. Surg. 2016, 69, 1305-1306. [CrossRef]

2. Zhang, W.; Xu, L.; Luo, T.; Wu, F.; Zhao, B.; Li, X. The etiology of Bell's palsy: A review. J. Neurol. 2020, 267, 1896-1905. [CrossRef]

3. Nellis, J.C.; Ishii, M.; Byrne, P.J.; Boahene, K.D.O.; Dey, J.K.; Ishii, L.E. Association among facial paralysis, depression, and of quality of life in facial plastic surgery patients. JAMA Facial Plast. Surg. 2017, 19, 190-196. [CrossRef]

4. Tiemstra, J.D.; Khatkhate, N. Bell's palsy: Diagnosis and management. Am. Fam. Physician 2007, 76, 997-1002.

5. Yoo, M.C.; Soh, Y.; Chon, J.; Lee, J.H.; Jung, J.; Kim, S.S.; You, M.W.; Byun, J.Y.; Kim, S.H.; Yeo, S.G. Evaluation of actors associated with favorable outcomes in adults with Bell palsy. JAMA Otolaryngol. Head Neck Surg. 2020, 146, 256-263. [CrossRef]

6. Heckmann, J.G.; Urban, P.P.; Pitz, S.; Guntinas-Lichius, O.; Gágyor, I. The diagnosis and treatment of idiopathic facial paresis (Bell's palsy). Deutsches Ärzteblatt Int. 2019, 116, 692-702.

7. Jabor, M.A.; Gianoli, G. Management of Bell's palsy. J. State Med. Soc. 1996, 148, 279-283.

8. Zandian, A.; Osiro, S.; Hudson, R.; Ali, I.M.; Matusz, P.; Tubbs, S.R.; Loukas, M. The neurologist's dilemma: A comprehensive clinical review of Bell's palsy, with emphasis on current management trends. Med. Sci. Monit. 2014, 20, 83-90. [PubMed]

9. Finkensieper, M.; Volk, G.F;; Guntinas-Lichius, O. Erkrankungen des nervus facialis. Laryngo-Rhino-Otologie 2012, 91, 121-142. [CrossRef]

10. Murakami, S.; Mizobuchi, M.; Nakashiro, Y.; Doi, T.; Hato, N.; Yanagihara, N. Bell palsy and herpes simplex virus: Identification of viral DNA in endoneurial fluid and muscle. Ann. Intern. Med. 1996, 124, 27-30. [CrossRef] [PubMed]

11. Kennedy, P.G. Herpes simplex virus type 1 and Bell's palsy-A current assessment of the controversy. J. Neurovirol. 2010, 16, 1-5. [CrossRef]

12. Numthavaj, P.; Thakkinstian, A.; Dejthevaporn, C.; Attia, J. Corticosteroid and antiviral therapy for Bell's palsy: A network meta-analysis. BMC Neurol. 2011, 11, 1. [CrossRef] [PubMed] 
13. Kim, S.H.; Jung, J.; Lee, J.H.; Byun, J.Y.; Park, M.S.; Yeo, S.G. Delayed facial nerve decompression for Bell's palsy. Eur. Arch. Otorhinolaryngol. 2016, 273, 1755-1760. [CrossRef]

14. Gantz, B.J.; Rubinstein, J.T.; Gidley, P.; Woodworth, G.G. Surgical management of Bell's palsy. Laryngoscope 1999, 109, 1177-1188. [CrossRef] [PubMed]

15. Zhong, W.; Yu, H.; Rao, X.; Wu, J.; Gou, Y.; Cui, H.; Huang, X.; Wang, L. Efficacy of manipulative acupuncture therapy monitored by LSCI technology in patients with severe Bell's palsy: A randomized controlled trial. Evid. Based Complement. Altern. Med. 2020, 2020, 6531743. [CrossRef] [PubMed]

16. Xu, S.B.; Huang, B.; Zhang, C.Y.; Du, P.; Yuan, Q.; Bi, G.J.; Zhang, G.B.; Xie, M.J.; Luo, X.; Huang, G.Y.; et al. Effectiveness of strengthened stimulation during acupuncture for the treatment of Bell palsy: A randomized controlled trial. CMAJ Can. Med. Assoc. J. 2013, 185, 473-479. [CrossRef]

17. Javaherian, M.; Attarbashi Moghaddam, B.; Bashardoust Tajali, S.; Dabbaghipour, N. Efficacy of low-level laser therapy on management of Bell's palsy: A systematic review. Lasers Med. Sci. 2020, 35, 1245-1252. [CrossRef] [PubMed]

18. Ravera, S.; Colombo, E.; Pasquale, C.; Benedicenti, S.; Solimei, L.; Signore, A.; Amaroli, A. Mitochondrial bioenergetic, photobiomodulation and trigeminal branches nerve damage, what's the connection? A review. Int. J. Mol. Sci. 2021, $22,4347$. [CrossRef]

19. Ravera, S.; Ferrando, S.; Agas, D.; De Angelis, N.; Raffetto, M.; Sabbieti, M.G.; Signore, A.; Benedicenti, S.; Amaroli, A. 1064 nm Nd:YAG laser light affects transmembrane mitochondria respiratory chain complexes. J. Biophotonics 2019, 12 , e201900101. [CrossRef]

20. Amaroli, A.; Pasquale, C.; Zekiy, A.; Utyuzh, A.; Benedicenti, S.; Signore, A.; Ravera, S. Photobiomodulation and oxidative stress: $980 \mathrm{~nm}$ diode laser light regulates mitochondrial activity and reactive oxygen species production. Oxid. Med. Cell Longev. 2021, 2021, 6626286. [CrossRef]

21. Hamblin, M.; Demidova, T. Mechanisms of low level light therapy. Proc. SPIE 2006, 6140, 614001.

22. Karu, T.I. Molecular mechanism of the therapeutic effect of low-intensity laser irradiation. Dokl. Akad. Nauk. SSSR 1986, 291, 1245-1249.

23. Amaroli, A.; Ravera, S.; Parker, S.; Panfoli, I.; Benedicenti, A.; Benedicenti, S. An 808-nm diode laser with a flat-top handpiece positively photobiomodulates mitochondria activities. Photomed. Laser Surg. 2016, 34, 564-571. [CrossRef]

24. Hanna, R.; Agas, D.; Benedicenti, S.; Ferrando, S.; Laus, F.; Cuteri, V.; Lacava, G.; Sabbieti, M.G.; Amaroli, A. A comparative study between the effectiveness of $980 \mathrm{~nm}$ photobiomodulation delivered by hand-piece with gaussian vs. flat-top profiles on osteoblasts maturation. Front. Endocrinol. 2019, 10, 92. [CrossRef]

25. Amaroli, A.; Arany, P.; Pasquale, C.; Benedicenti, S.; Bosco, A.; Ravera, S. Improving consistency of photobiomodulation therapy: A novel flat-top beam hand-piece versus standard gaussian probes on mitochondrial activity. Int. J. Mol. Sci. 2021, 22, 7788. [CrossRef]

26. Amaroli, A.; Ravera, S.; Parker, S.; Panfoli, I.; Benedicenti, A.; Benedicenti, S. 808-nm laser therapy with a flat-top handpiece photobiomodulates mitochondria activities of Paramecium primaurelia (Protozoa). Lasers Med. Sci. 2016, 31, 741-747. [CrossRef]

27. Ferrando, S.; Agas, D.; Mirata, S.; Signore, A.; De Angelis, N.; Ravera, S.; Utyuzh, A.S.; Parker, S.; Sabbieti, M.G.; Benedicenti, S.; et al. The $808 \mathrm{~nm}$ and $980 \mathrm{~nm}$ infrared laser irradiation affects spore germination and stored calcium homeostasis: A comparative study using delivery hand-pieces with standard (Gaussian) or flat-top profile. J. Photochem. Photobiol. 2019, 199, 111627. [CrossRef] [PubMed]

28. Amaroli, A.; Ferrando, S.; Pozzolini, M.; Gallus, L.; Parker, S.; Benedicenti, S. The earthworm Dendrobaena veneta (Annelida): A new experimental-organism for photobiomodulation and wound healing. Eur. J. Histochem. 2018, 62, 2867. [CrossRef] [PubMed]

29. Abdel Hamid, M.A.; Zaied, A.A.; Zayet, M.K.; Abdelmageed, H.; Hassan, E.A.; Amaroli, A. Efficacy of flat-top hand-piece using $980 \mathrm{~nm}$ diode laser photobiomodulation on socket healing after extraction: Split-mouth experimental model in dogs. J. Photochem. Photobiol. 2021, 97, 627-633. [CrossRef]

30. Pasquale, C.; Colombo, E.; Benedicenti, S.; Signore, A.; Amaroli, A. 808-Nm near-infrared laser photobiomodulation versus switched-off laser placebo in major aphthae management: A randomized double-blind controlled trial. Appl. Sci. 2021, 11, 4717. [CrossRef]

31. Fini Storchi, I.; Frosecchi, M.; Bovis, F.; Zekiy, A.; Benedicenti, S.; Amaroli, A.; Convissar, R.A. Snoring and sleep-related symptoms: A novel non-invasive $808 \mathrm{~nm}$ wavelength diode laser non-ablative outpatient treatment. A prospective pilot-study on 45 patients. Photonics 2021, 8, 69. [CrossRef]

32. Baugh, R.F.; Basura, G.J.; Ishii, L.E.; Schwartz, S.R.; Drumheller, C.M.; Burkholder, R.; Deckard, N.A.; Dawson, C.; Driscoll, C.; Gillespie, M.B.; et al. Clinical practice guideline: Bell's palsy. Otolaryngol. Head Neck Surg. 2013, 149 (Suppl. 3), S1-S27. [CrossRef] [PubMed]

33. Lacombe, H. Evaluation de la paralysie faciale périphérique: Échelle de House-Brackmann [Evaluation of peripheral facial palsy: The House-Brackmann scale]. Revue Neurol. 2000, 156, 806-808.

34. Gronseth, G.S.; Paduga, R. Evidence-based guideline update: Steroids and antivirals for bell palsy: Report of the guideline development Subcommittee of the American Academy of neurology. Neurology 2012, 79, 2209-2213. [CrossRef] [PubMed]

35. Leclère, F.M.; Magalon, G.; Philandrianos, C.; Unglaub, F.; Servell, P.; Mordon, S. Prospective ex-vivo study on thermal effects in human skin phototypes II, IV and VI: A comparison between the 808, 1064, 1210 and 1320-nm diode laser. J. Cosmet. Laser Ther. 2012, 14, 7-13. [CrossRef] [PubMed] 
36. Prud'hon, S.; Kubis, N. Bell's palsy. Rev. Med. Interne 2019, 40, 28-37. [CrossRef] [PubMed]

37. Delgado Castillo, M.; Sanchez del Rio, M.; de Jesús Díaz García, A.; González Quevedo, A.; Sánchez López, J.V. Usefulness of magnetic field and laser for the treatment of idiopathic peripheral facial palsy. Fisioterapia 2013, 35, 252-257. [CrossRef]

38. Teixeira, L.J.; Valbuza, J.S.; Prado, G.F. Physical therapy for Bell's palsy (idiopathic facial paralysis). Cochrane Database Syst. Rev. 2011, 12, CD006283. [CrossRef]

39. Tanganeli, J.P.C.; de Oliveira, S.S.I.; da Silva, T.; Fernandes, K.P.S.; Motta, L.J.; Bussadori, S.K. Complete and fast recovery from idiopathic facial paralysis using laser-photobiomodulation. Case Rep. Dent. 2020, 2020, 9867693. [CrossRef]

40. Kumar, S. Effect of class IV LASER on Bell's palsy: A case series. Indian J. Phys. Ther. Res. 2019, 1, 55-58.

41. Aghamohamdi, D.; Fakhari, S.; Farhoudi, M.; Farzin, H. The Efficacy of low-level laser therapy in the treatment of Bell's palsy in diabetic patients. J. Lasers Med. Sci. 2020, 11, 310-315. [CrossRef]

42. Ordahan, B.; Karahan, A.Y. Role of low-level laser therapy added to facial expression exercises in patients with idiopathic facial (Bell's) palsy. J. Lasers Med. Sci. 2017, 32, 931-936. [CrossRef]

43. Koyuncu, O.O.; Perlman, D.H.; Enquist, L.W. Efficient retrograde transport of pseudorabies virus within neurons requires local protein synthesis in axons. Cell Host Microbe 2013, 13, 54-66. [CrossRef] [PubMed]

44. Koyuncu, O.O.; Song, R.; Greco, T.M.; Cristea, I.M.; Enquist, L.W. The number of alphaherpesvirus particles infecting axons andthe axonal protein repertoire determines the outcome of neuronal infection. mBio 2015, 6, e00276-15. [CrossRef]

45. Fang, F.; Liu, C.Y.; Zhang, J.; Zhu, L.; Qian, Y.X.; Yi, J.; Xiang, Z.H.; Wang, H.; Jiang, H. Involvement of MAPK ERK activation in upregulation of water channel protein aquaporin 1 in a mouse model of Bell's palsy. J. Mol. Neurosci. 2015, 56, 164-176. [CrossRef]

46. Masub, N.; Austin, E.; Huang, A.; Jagdeo, J. High-fluence light emitting diode-red light inhibits cell cycle progression in human dermal fibroblasts. J. Biophotonics 2021, 14, e202000359. [CrossRef]

47. Louzeiro, G.C.; Teixeira, D.D.S.; Cherubini, K.; de Figueiredo, M.A.Z.; Salum, F.G. Does laser photobiomodulation prevent hyposalivation in patients undergoing head and neck radiotherapy? A systematic review and meta-analysis of controlled trials. Crit. Rev. Oncol. Hematol. 2020, 156, 103115. [CrossRef]

48. Luo, G.Y.; Sun, L.; Wei, E.X.; Tan, X.; Liu, T.C. The effects of low-intensity He-Ne laser irradiation on erythrocyte metabolism. Lasers Med. Sci. 2015, 30, 2313-2318. [CrossRef]

49. Grewal, D.S. Bell's palsy-tertiary ischemia: An etiological factor in residual facial palsy. Indian J. Otolaryngol. Head Neck Surg. 2018, 70, 374-379. [CrossRef] [PubMed]

50. Wang, R.; Dong, Y.; Lu, Y.; Zhang, W.; Brann, D.W.; Zhang, Q. Photobiomodulation for global cerebral ischemia: Targeting mitochondrial dynamics and functions. Mol. Neurobiol. 2019, 56, 1852-1869. [CrossRef] [PubMed]

51. Amaroli, A.; Ravera, S.; Baldini, F.; Benedicenti, S.; Panfoli, I.; Vergani, L. Photobiomodulation with 808-nm diode laser light promotes wound healing of human endothelial cells through increased reactive oxygen species production stimulating mitochondrial oxidative phosphorylation. Lasers Med. Sci. 2019, 34, 495-504. [CrossRef]

52. Colombo, E.; Signore, A.; Aicardi, S.; Zekiy, A.; Utyuzh, A.; Benedicenti, S.; Amaroli, A. Experimental and clinical applications of red and near-infrared photobiomodulation on endothelial dysfunction:a review. Biomedicines 2021, 9, 274. [CrossRef] [PubMed]

53. Moriyama, H.; Mitsukawa, N.; Itoh, M.; Otsuka, N. A view of the therapy for Bell's palsy based on molecular biological analyses of facial muscles. J. Int. Adv. Otol. 2017, 13, 414-416. [CrossRef]

54. Persson, A.K.; Kim, I.; Zhao, P.; Estacion, M.; Black, J.A.; Waxman, S.G. Sodium channels contribute to degeneration of dorsal root ganglion neurites induced by mitochondrial dysfunction in an in vitro model of axonal injury. J. Neurosci. 2013, 33, 19250-19261. [CrossRef] [PubMed]

55. Amaroli, A.; Parker, S.; Dorigo, G.; Benedicenti, A.; Benedicenti, S. Paramecium: A promising non-animal bioassay to study the effect of $808 \mathrm{~nm}$ infrared diode laser photobiomodulation. Photomed. Laser Surg. 2015, 33, 35-40. [CrossRef] [PubMed]

56. Amaroli, A.; Ferrando, S.; Benedicenti, S. Photobiomodulation affects key cellular pathways of all life-forms: Considerations on old and new laser light targets and the calcium issue. Photochem. Photobiol. 2019, 95, 455-459. [CrossRef] [PubMed]

57. Amaroli, A.; Agas, D.; Laus, F.; Cuteri, V.; Hanna, R.; Sabbieti, M.G.; Benedicenti, S. The effects of photobiomodulation of 808 nm diode laser therapy at higher fluence on the in vitro osteogenic differentiation of bone marrow stromal cells. Front. Physiol. 2018, 9, 123. [CrossRef] [PubMed]

58. Amaroli, A.; Ferrando, S.; Hanna, R.; Gallus, L.; Benedicenti, A.; Scarfi, S.; Pozzolini, M.; Benedicenti, S. The photobiomodulation effect of higher-fluence 808-nm laser therapy with a flat-top handpiece on the wound healing of the earthworm Dendrobaena veneta: A brief report. Lasers Med. Sci. 2018, 33, 221-225. [CrossRef] [PubMed]

59. Amaroli, A.; Marcoli, M.; Venturini, A.; Passalacqua, M.; Agnati, L.F.; Signore, A.; Raffetto, M.; Maura, G.; Benedicenti, S.; Cervetto, C. Near-infrared laser photons induce glutamate release from cerebrocortical nerve terminals. J. Biophotonics 2018, 11, e201800102. [CrossRef]

60. Mathes, T.; Pieper, D. Clarifying the distinction between case series and cohort studies in systematic reviews of comparative studies: Potential impact on body of evidence and workload. BMC Med. Res. Methodol. 2017, 17, 107. [CrossRef] 